\title{
Isothiocyanates: A Chemical Class of Potential Nutraceuticals
}

\author{
Costas Ioannides*, Natalya Hanlon and Nattaya Konsue \\ Molecular Toxicology Group, Faculty of Health and Medical Sciences, University of Surrey, Guildford, Surrey, GU2 \\ $7 X H, U K$
}

\begin{abstract}
Isothiocyanates comprise the most promising class of chemopreventive phytochemicals. They are encountered at substantial amounts in cruciferous vegetables where they exist in the form of glucosinolates. Epidemiological studies have linked consumption of isothiocyanates to low cancer incidence at a number of sites. Furthermore, laboratory studies in animal models of cancer have established that various isothiocyanates can effectively antagonise the carcinogenicity of chemicals. A principal mechanism of action of these chemicals is to modulate the metabolism of chemical carcinogens so as to favour their metabolic detoxification. In this mini review we discuss the ability of isothiocyanates to influence carcinogen-metabolising enzyme systems, such as cytochromes P450 and conjugation systems, at dietary levels of exposure.
\end{abstract}

Keywords: Chemoprevention, Isothiocyanates, Glucosinolates, Cruciferous vegetables, Bioactivation, Cytochromes P450.

\section{INTRODUCTION}

Humans are continuously and involuntarily exposed to a vast array of structurally diverse chemicals, diet being the main source. Although anthropogenic chemicals attract most attention, the vast majority of chemicals to which humans are exposed are, in fact, naturally-occurring, largely phytochemicals. Such chemicals can not be exploited by the body so as to provide benefit and assist normal physiological functions, and are frequently referred to as anutrients, but can be potentially detrimental to health. Diet is, indeed, the principal source of human exposure to carcinogenic chemicals. Such carcinogenic compounds may be inherent to the diet, e.g. safrole in some spices and hydrazines in edible mushroom, or contaminants, e.g. mycotoxins, but the most important source is the processing and, especially, cooking of food. Cooking of highly proteinaceous food such as meat and fish at high temperatures, such as those achieved during frying, grilling and barbecuing results in the generation of established carcinogenic compounds such as polycyclic aromatic hydrocarbons and heterocyclic amines.

\section{BIOACTIVATION AND DETOXICATION OF CHEMICAL CARCINOGENS}

Once a chemical carcinogen gains entry into the systemic circulation, the first response of the body is to attempt to eliminate it by metabolically converting it to hydrophilic metabolites that are more easily excreted, thus facilitating its removal from the body. However, certain pathways of metabolism can also lead to the production of genotoxic metabolites.

\footnotetext{
*Address correspondence to this author at the Molecular Toxicology Group, Faculty of Health and Medical Sciences, University of Surrey, Guildford, Surrey, GU2 7XH, UK; Tel: +44 1483 689709; Fax: +44 1483 686401;

E-mail: c.ioannides@surrey.ac.uk
}

Chemical carcinogens, including polycyclic aromatic hydrocarbons and heterocyclic amines, in their parent form lack the necessary chemical activity that would allow them to interact with DNA and set into motion the complex processes that eventually lead to carcinogenesis, and this constitutes a toxicological paradox. The solution of this conundrum emerged in the early 1970s when it was demonstrated that these un-reactive compounds can acquire chemical reactivity through metabolism that takes place within the living organism, primarily in the liver. These reactive intermediates are electrophiles, and since they are generated intracellularly, they can readily and irreversibly interact with DNA and other macromolecules with adverse consequences. The process through which inert chemicals are biotransformed to reactive intermediates capable of causing cellular damage is known as 'metabolic activation' or 'bioactivation', and for these chemicals, carcinogenicity is inextricably linked to their metabolism (Fig. 1). The generated reactive intermediates may interact directly with DNA to form adducts which, if they escape the repair mechanisms of the cell, may give rise to mutations. Reactive intermediates of chemicals may also induce DNA damage indirectly through an alternative mechanism that involves interaction with molecular oxygen to produce highly reactive, short-lived oxygen species, such as the hydroxyl radical. The hydroxyl radical, as well as other reactive oxygen species, can cause DNA damage similar to that resulting from the interaction with the reactive intermediates.

Although a number of enzyme systems may catalyse the bioactivation of chemical carcinogens, the most important is cytochromes P450 [1]. The same enzyme system can also metabolise carcinogenic compounds through alternative pathways that lead to the formation of biologically inactive, readily excretable metabolites. For example, the heterocyclic amine 2-amino-3-methylimidazo-[4,5-f]quinoline (IQ) is metabolised by cytochrome P450 through N-hydroxylation, an activation pathway leading to the generation of the highly 


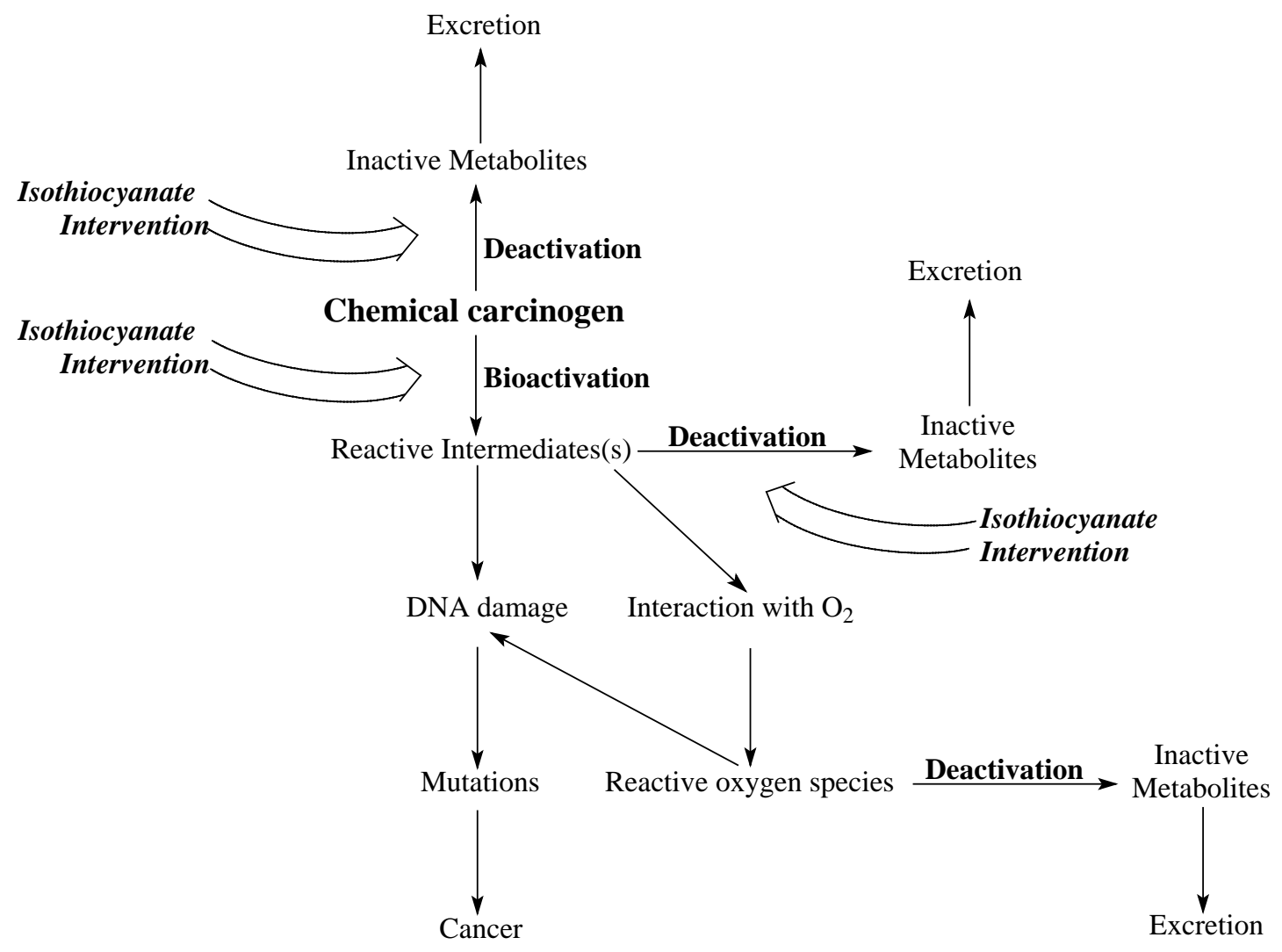

Fig. (1). Bioactivation and deactivation of chemical carcinogens: potential sites of isothiocyanate intervention.

genotoxic nitrenium ion, or through ring-hydroxylation at the 5-position which is a deactivation pathway; this product is conjugated with sulphate or glucuronide and excreted (Fig. 2). A principal attribute of the cytochrome P450 system is the unprecedented broad substrate specificity it displays, being capable of efficiently catalysing the metabolism of chemicals varying enormously in shape and size. It achieves this by existing as a superfamily comprising a number of enzymes, each with different substrate specificity. This cytochrome P450 superfamily is divided into a number of families, which in turn are subdivided into subfamilies, each of which may consist of one or more enzymes (isoforms). Classification of cytochrome P450 enzymes within families and subfamilies is carried out strictly on the basis of primary sequence homology, with no consideration of their function in xenobiotic metabolism. For example, CYP3A4 enzyme denotes a cytochrome $\mathrm{P} 450$ protein belonging to family 3 , subfamily $A$ and is protein 4 . The families responsible for the metabolism of xenobiotics such as chemical carcinogens are CYP1 to CYP3. A summary of the role of each cytochrome P450 subfamily plays in the metabolism of chemical carcinogens is illustrated in Table 1.

As a defensive mechanism, both the parent carcinogens (vide supra) as well as the reactive intermediates may be subjected to metabolism through alternative pathways that produce hydrophilic, biologically inactive metabolites that can be readily excreted (Fig. 1). In this way the cell hinders the interaction of the reactive intermediates with DNA. The most effective protective mechanism against chemical reactive intermediates is detoxication through conjugation with endogenous glutathione, a nucleophilic tripeptide. Glutathione conjugates are excreted into the urine and bile usually following further processing to form mercapturates. The fact that the cellular concentration of glutathione are rather high (about $10 \mathrm{mM}$ ) testifies to the importance of this reaction in the body's defence against toxic chemicals. Another enzyme system important in detoxication is quinone reductase, which prevents quinones from interacting with molecular oxygen to generate reactive oxygen species (Fig. 3). Quinones, oxidation products of phenolic metabolites of aromatic hydrocarbons, can undergo one-electron reductions to form the semiquinone radical, which may directly attack DNA but can cause DNA damage also indirectly through reactive oxygen species that are produced as a consequence of their interaction with molecular oxygen. Quinone reductase protects against quinone-derived reactive oxygen species by converting the quinone to the hydroquinone through a two-electron reduction (Fig. 3).

Consequently, the levels of reactive intermediates generated depend on the competing rates of bioactivation on one hand, and detoxication of the parent compound and reactive intermediate(s) on the other. If the enzyme profile of an individual favours the bioactivation pathway of a carcinogen, then he would be vulnerable to its carcinogenicity; if, however, the detoxication pathways predominate then he would display resistance.

\section{DIETARY CHEMICALS AS MODULATORS OF CARCINOGEN METABOLISM}

Clearly a feasible approach to prevent chemicallyinduced carcinogenesis is to limit the amount of reactive intermediates available for interaction with DNA. This can be achieved by either suppressing the bioactivation of chemicals and/or stimulating the detoxication pathways. 


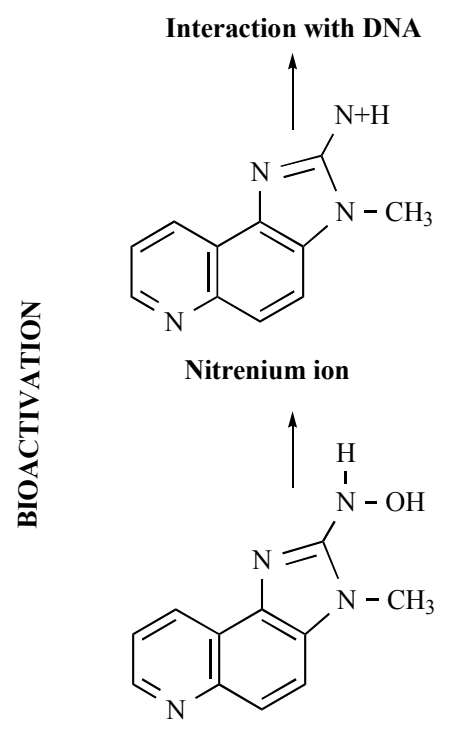<smiles>Cn1c(N)nc2c3cccnc3ccc21</smiles>

IQ

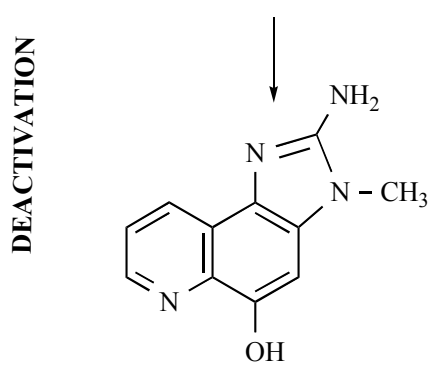

5-Hydroxy IQ

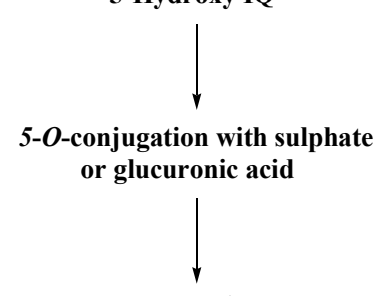

Excretion

Fig. (2). Cytochrome P450-mediated bioactivation and deactivation of IQ.

Could this balance of activation/detoxication be modulated by dietary means in such a way so as to facilitate detoxication at the expense of bioactivation? In the mid 1970s, Tapan Basu, who is honoured in the current issue of the journal, working at the time with John Dickerson and Dennis Parke at the University of Surrey, used biphenyl as a model substrate to establish that the metabolism of xenobiotics could be manipulated by altering the macromolecule composition of diets. Maintaining rats on low-protein diets for at least two weeks led to elevated metabolism of biphenyl through 4hydroxylation, a detoxification process [2]. The metabolism of the same substrate was suppressed, however, when starch was replaced with glucose, fructose or sucrose [3]. Subsequent studies indicated that also in volunteers altering the protein content impacted on the metabolism of drugs [4]. Basu then turned his attention to micronutrients, and demonstrated that large doses of ascorbic acid impaired both the 4hydroxylation of biphenyl and the $\mathrm{N}$-demethylation of ethylmorphine in guinea pigs [5]. Thus these studies revealed the potential of the diet to influence the metabolism of drugs and chemical carcinogens, altering the balance of activation/ deactivation [6]. 
Table 1. Rat and Human Xenobiotic-Metabolising Cytochromes P450 and Their Role in the Bioactivation of Chemical Carcinogens

\begin{tabular}{|c|c|c|c|c|}
\hline $\begin{array}{c}\text { Cytochrome P450 } \\
\text { Subfamily }\end{array}$ & Human Proteins & Rat Proteins & $\begin{array}{c}\text { Role in Chemical } \\
\text { Carcinogenesis }\end{array}$ & $\begin{array}{c}\text { Major Classes of Activated } \\
\text { Carcinogens }\end{array}$ \\
\hline \hline CYP1A & $1 \mathrm{~A} 1,1 \mathrm{~A} 2$ & $1 \mathrm{~A} 1,1 \mathrm{~A} 2$ & Very extensive & PAH, AA, HA, MC, NNK, AAB \\
\hline CYP1B & $1 \mathrm{~B} 1$ & $1 \mathrm{~B} 1$ & Very extensive & PAH, AA, HA, MC, NNK, \\
AAB, Oestrogens
\end{tabular}

PAH, Polycyclic aromatic hydrocarbons; AA, Aromatic amines; HA, Heterocyclic amines; MC, Mycotoxins; NNK, 4-(methylnitrosamino)-1-(3-pyridyl)-1-butanone; AAB, Aminoazobenzenes; OP, Oxazophosphorines; HH, Halogenated hydrocarbons; PA, Pyrrolizidine alkaloids.

Adapted from reference [1].

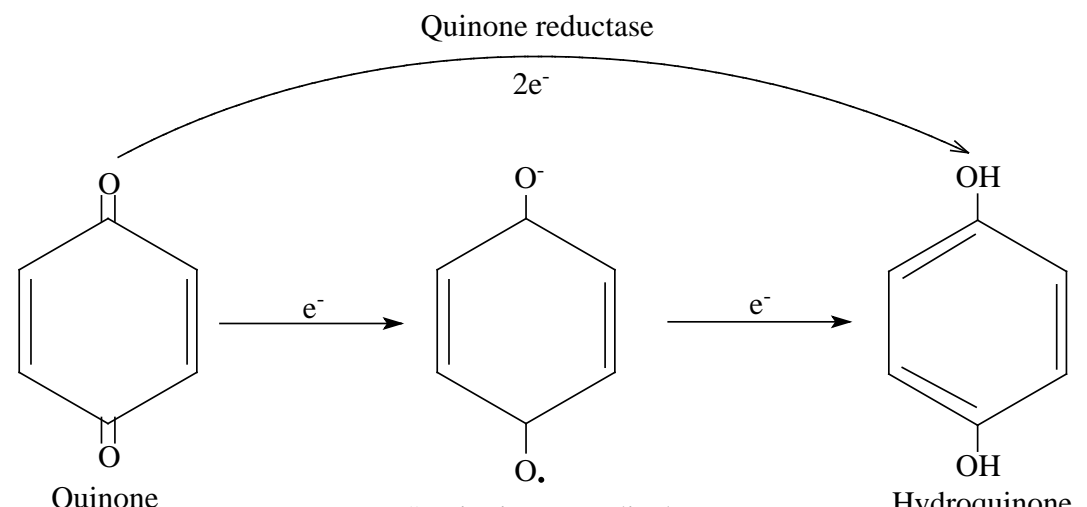

Quinone

Semiquinone Radical

Hydroquinone

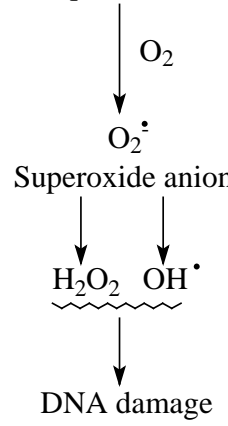

Fig. (3). Bioactivation and deactivation of quinones.

Further work revealed that dietary anutrients had also the potential to modulate carcinogen-metabolising enzymes, both stimulating and suppressing metabolism. Such compounds include organosulphates in garlic, indoles and isothiocyanates in cruciferous vegetables, caffeine in coffee, bergamottins in grapefruit juice and methylenedioxyphenyl compounds present in common spices $[7,8]$. Many of these phytochemicals have been shown to modulate the metabolism of xenobiotics, including medicinal drugs and chemical carcinogens, even following exposure to dietary levels. In 
seminal studies that commenced in the 1970s it was demonstrated that the feeding of volunteers with diets supplemented with cruciferous vegetables, such as cabbage and Brussels sprouts, modulated the metabolism of drugs like phenacetin and paracetamol [5, 9]. In subsequent studies, human volunteers consuming daily $500 \mathrm{~g}$ of lightly cooked broccoli for 10-12 days exhibited elevated metabolism of caffeine, presumably by up-regulating CYP1A2, a liverspecific cytochrome P450 enzyme that functions as the principal catalyst of the oxidation of caffeine $[10,11]$.Consumption of watercress ( $100 \mathrm{~g} /$ day) for only a week suppressed the metabolism of chlorzoxazone in human volunteers, which is catalysed by CYP2E1 [12]. More recent work, also conducted in human volunteers, has established the potential of vegetables to also alter the metabolism of carcinogens. Consumption of cruciferous vegetables such as Brussels sprouts and broccoli modulated the metabolism of the carcinogenic heterocyclic amines 2-amino-3,5-dimethylimidazo[4,5-f]quinoxaline (MeIQx) and 2-amino-1methyl-6-phenylimidazo[4,5-b]pyridine (PhIP) by stimulating cytochrome P450 and glucuronosyl transferase activities $[13,14]$; the impact of such changes of metabolism on the carcinogenic activity of these chemicals remains to be established.

\section{ISOTHIOCYANATES}

A large number of dietary phytochemicals have been recognised as having potential chemopreventive activity, and in laboratory studies they could antagonise the carcinogenicity of chemicals in animal models, explaining the low cancer incidence associated with the chronic consumption of diets rich in fruit and vegetable content. In worldwide studies relating cancer incidence to vegetable consumption, cruciferous vegetables have been closely linked to low cancer incidence at many sites; it is becoming increasingly evident, however, that the protective effect may depend on the genetic make-up of the individual. The potential of these vegetables to protect against a number of cancers at a number of sites, including lung, oesophagus, small intestine, colon, pancreas, liver, prostate, bladder and mammary gland in humans, has been recognised in many epidemiological studies conducted worldwide [15-19]. A major class of chemopreventive agents present in cruciferous vegetables are the isothiocyanates; these are present in these vegetables in the form of glucosinolates, sulphur-containing precursors, but when the vegetables are disturbed, e.g. during harvesting, cutting and chewing, the enzyme myrosinase ( $\beta$-thioglucoside glucohydrolase) comes into contact with the glucosinolate converting it into the corresponding isothiocyanate (Fig. 4). Microorganisms residing in the human intestine have also the potential to catalyse this reaction thus contributing to the release of the isothiocyanate from its parent glucosinolate [20]. Isothiocyanates are well absorbed and achieve very good bioavailability [21-24] Moreover, isothiocyanates are well tolerated and do not induce any adverse effects [25].

The chemopreventive mechanism of action of isothiocyanates appears to be multifactorial, influencing all stages of chemical carcinogenesis, including impairment of the initiation stage $[26,27]$. One of the most important mechanisms of their chemopreventive activity relates to their ability to limit the availability of the reactive intermediates of chemical carcinogens, thus protecting the DNA from their deleterious effect; this can be achieved by either inhibiting the formation of reactive intermediates and/or by stimulating their detoxication (Fig. 1).

\section{INHIBITION OF THE CYTOCHROME P450- MEDIATED BIOACTIVATION OF CHEMICAL CARCINOGENS BY ISOTHIOCYANATES}

In our laboratory attention focussed on three isothiocyanates, namely sulforaphane and the structurally related erucin, both having an aliphatic substituent, and phenethyl isothiocyanate (PEITC), having an aromatic substituent (Table 2). Sulforaphane is the 'benchmark' isothiocyanate, having been the most extensively studied and believed to be the most potent anticarcinogen among those studied. Its principal source is broccoli which is mostly consumed cooked by boiling, and this procedure results in marked loss of glucosinolates which leach into the cooking water, although other cooking processes such as steaming and microwaving have minimal effects [28]. More importantly, cooking of vegetables denatures myrosinase, the enzyme that converts the glucosinolates to the active isothiocyanates

\begin{tabular}{|c|c|}
\hline $\mathrm{R}-\mathrm{C}-\mathrm{S}-\mathrm{Glucose}$ & \\
\hline$K_{11}^{-C}-S-$ Giucose & Plant/Microbial \\
\hline$\underset{\mathrm{I}}{\mathrm{N}}$ & myrosinase \\
\hline $\mathrm{OSO}_{3}^{-}$ & \\
\hline
\end{tabular}

\section{Glucosinolate}

Fig. (4). Generation of isothiocyanates from glucosinolates.

Table 2. Extensively Studied Naturally-Occurring Isothiocyanates

\begin{tabular}{|c|c|c|c|}
\hline Isothiocyanate & Structure & Parent Glucosinolate & Principal Food Source \\
\hline \hline Sulforaphane & $\mathrm{CH}_{3} \mathrm{SO}\left(\mathrm{CH}_{2}\right)_{4} \mathrm{~N}=\mathrm{C}=\mathrm{S}$ & Glucoraphanin & Broccoli \\
\hline Erucin & $\mathrm{CH}_{3} \mathrm{~S}\left(\mathrm{CH}_{2}\right)_{4} \mathrm{~N}=\mathrm{C}=\mathrm{S}$ & Glucoerucin & Rocket (arugula) \\
\hline Phenethyl isothiocyanate & $\mathrm{C}_{6} \mathrm{H}_{5}\left(\mathrm{CH}_{2}\right)_{2} \mathrm{~N}=\mathrm{C}=\mathrm{S}$ & Gluconasturtiin & Watercress \\
\hline
\end{tabular}


[29] As a result of these two effects, the bioavailability of isothiocyanates is drastically decreased. Indeed, the bioavailability of isothiocyanates from broccoli markedly decreased after steaming [30]. In contrast, erucin and phenethyl isothiocyanate are encountered in rocket (arugula) and watercress respectively, both of which are usually consumed raw so that the losses associated with cooking are avoided.

In in vitro studies employing rat and human hepatocytes sulforaphane led to inhibition of the activity of the CYP1A, CYP2B, CYP2E and CYP3A subfamilies [31, 32]. In in vivo studies, however, exposure of rats to dietary doses of either sulforaphane or erucin did not result in any changes in CYP1A or CYP2B activities in either liver or lung [33, 34]. Extensive studies in precision-cut rat and human liver, and rat lung slices, utilising a wide range of isothiocyanate concentrations, further demonstrated the inability of these compounds to modulate cytochrome P450 activity [35, 36]. However, when the same cytochrome P450 enzymes were monitored at the protein level, both isothiocyanates increased CYP1A expression, and the lack of a concomitant increase in activity was demonstrated to be due to the fact that both these compounds are mechanism-based inhibitors [33, 34]. Clearly, suppression of cytochrome P450 activity, leading to impaired bioactivation of chemical carcinogens is not a viable mechanism for the chemopreventive activity of these aliphatic isothiocyanates.

The most extensively studied isothiocyanate with an aromatic substituent is PEITC. A single large dose of this isothiocyanate impaired CYP2E1 activity but elevated CYP2B1 in rodents $[37,38]$, whereas following chronic intake in mice an increase in hepatic CYP2E1 was noted [39]. In studies conducted in our laboratory, exposure of rats through the diet to dietary doses of PEITC that represent human intake, CYP1A2 activity declined, although at higher doses no effect was evident; at relatively higher doses, however, many other cytochrome P450 enzymes were influenced, including elevation of CYP2B and CYP3A, and suppression of CYP2E1 activities [40]. It should be pointed out that, similar to erucin and sulforaphane, PEITC is a mechanism-based inhibitor [40, 41]. It is thus apparent that the effects of isothiocyanates on the cytochrome P450 system are influenced by the nature of the substituent.

\section{DETOXICATION OF REACTIVE INTERMEDIATES AS A POTENTIAL MECHANISM OF THE CHEMO- PREVENTIVE ACTIVITY OF ISOTHIOCYANATES}

An alternative mechanism through which isothiocyanates can elicit their chemopreventive activity is by stimulating the detoxication of the reactive intermediates of chemical carcinogens. As already discussed, enzymes such as glutathione $S$-transferases and quinone reductase enable the body to neutralise reactive intermediates such as epoxides and quinones respectively. In fact, induction of phase II enzymes correlates well with the chemopreventive potential of individual isothiocyanates [42].

Quinone reductase is probably the most inducible enzyme by isothiocyanates; erucin, sulforaphane and phenethyl isothiocyanate stimulated the activity of this enzyme in the liver of rats following intake of low dietary doses, which is paralleled by a rise in enzyme protein levels [33, 34, 40, 43].
However, although erucin and sulforaphane up-regulate this enzyme also in the lung [34, 36, 43], no such increase was observed following exposure even to high doses of phenethyl isothiocyanate $[37,40]$, indicating that induction of quinone reductase by PEITC is tissue-specific.

The potential of isothiocyanates to boost glutathione $S$ transferase activity is considered to be a central mechanism of their chemopreventive activity. Numerous studies established the potential of isothiocyanates to elevate this activity in a number of tissues [37, 44,]. However, treatment of rats with low, dietary levels of sulforaphane or erucin failed to increase activity in either liver or lung [33,34], whereas phenethyl isothiocyanate doubled the activity, but only in the liver [40]. However, in precision-cut slices both erucin and sulforaphane stimulated the activity of this enzyme, in both liver and lung slices, even at concentrations as low as 1 and $2.5 \mu \mathrm{M}(\mu \mathrm{mol} / \mathrm{L})$ respectively $[36,43]$. It is important to emphasise that in pharmacokinetic studies, treatment of rats with a single low dietary dose of sulforaphane and PEITC attained peak plasma levels of 0.3 and $3 \mu \mathrm{M}(\mu \mathrm{mol} / \mathrm{L})$ respectively [21, 23]. This difference in plasma concentrations may explain, at least partly, the disparity in the effects of these isothiocyanates on hepatic glutathione $S$-transferase activity in rats. It is also relevant to point out that in studies conducted in healthy volunteers consumption of $300 \mathrm{ml}$ of raw, liquidised broccoli florets, obtained from a local supermarket, achieved peak plasma levels of only $0.07 \mu \mathrm{M}$ $(\mu \mathrm{mol} / \mathrm{L})$; moreover, plasma levels did not rise even when the volunteers consumed the same amount of broccoli for 10 days [22]. Thus, bearing in mind the low plasma levels achieved after dietary intake of isothiocyanates, it may be inferred that detoxication of reactive intermediates through increased glutathione $S$-transferase activity is unlikely to be a dominant mechanism of the chemopreventive activity of isothiocyanates.

The question that is essential to address is whether human liver and lung carcinogen-metabolising enzyme systems respond in the same way to isothiocyanates as observed in rats. Limited studies, employing only two human livers and utilising the precision-cut tissue system indicated that this may not always be the case. When rat liver slices were incubated with sulforaphane or erucin, there was a rise in quinone reductase activity paralleled by a similar rise in enzyme protein levels, as already discussed; however, following incubation of the these isothiocyanates with human slices from two livers, under identical conditions, in neither liver was a rise in quinone reductase activity noted, and in only one of the human livers there was a modest rise in protein levels observed, much lower that what was recorded in the rat liver [43]. Similarly, in only one of the human livers glutathione $S$-transferase activity and enzyme protein levels were elevated; moreover, only in the liver from this donor exposure to these isothiocyanates led to an increase in total glutathione levels [43]. Evidently, more extensive studies, utilising a far larger number of human livers need to be conducted to ascertain whether the effect of isothiocyanates on human carcinogen-metabolising enzyme systems are comparable to those reported in rat liver. It is conceivable that the up-regulation of these enzymes in human liver is subject to genetic polymorphism. 


\section{CONCLUSIONS}

Strong epidemiological evidence has linked dietary consumption of cruciferous vegetables to low cancer incidence; isothiocyanates, which are present in these vegetables in substantial amounts [45], are considered to be important contributors to the chemopreventive activity ascribed to these vegetables. In animal studies, these compounds have antagonised the initiation of lung tumours induced by polycyclic aromatic hydrocarbons [46]. A pathway of bioactivation of this class of carcinogenic compounds involves oxidation to form quinones that may enter redox cycling to form semiquinones and reactive oxygen species. Up-regulation of quinone reductase, which prevents this pathway by converting the quinones to hydroquinones, by isothiocyanates that occurs even following exposure to low doses, may thus be responsible for the isothiocyanate-mediated suppression of polycyclic aromatic hydrocarbon-induced cancers. Other enzyme systems such as glutathione $S$-transferases and cytochromes P450, in most cases are modulated only by relatively higher doses and so are unlikely to constitute a predominant mechanism at dietary levels of intake.

It is encouraging that, in both animals and humans intake of dietary levels of cruciferous vegetables or individual isothiocyanates, impacted on the metabolism of heterocyclic amines $[13,14,47]$. It is becoming apparent that the cytochrome P450-mediated oxidation of these carcinogens is not the pathway perturbed by isothiocyanates, but stimulated deactivation through conjugation reactions. Studies to ascertain whether exposure to isothiocyanates influences enzyme systems such as sulphotransferases, acetylases and glucuronosyl transferases would greatly enhance our understanding of how precisely these phytochemicals modify carcinogen metabolism.

However, it is important to bear in mind that cruciferous vegetables contain a number of isothiocyanates whereas in animal studies almost always a single isothiocyanate is investigated at a time. Although dietary intake of cruciferous vegetables/isothiocyanates results in low plasma levels, it may be that the total burden of isothiocyanates is considerably higher, giving rise to biological effects not encountered with single compounds. Moreover, the possibility that interactions between isothiocyanates, or even with other chemicals present in these vegetables, both of a synergistic and antagonistic nature, occur can not be excluded, and may have a major impact on the anticarcinogenic potential and merit investigation. Finally, it is essential that the levels of intake that modulate carcinogen metabolism are defined, so that science-based advice is made available to the consumer relating to the optimum doses of these neutraceuticals.

\section{ACKNOWLEDGEMENTS}

The authors acknowledge with gratitude the financial support of the Association for International Cancer Research. Nattaya Konsue gratefully acknowledges financial support from the Ministry of Science and Technology, Royal Thai Government.

\section{REFERENCES}

[1] Ioannides C, Lewis DFV. Cytochromes P450 in the bioactivation of chemicals. Curr Top Med Chem 2004; 4: 1767-88.
[2] Dickerson JWT, Basu TK, Parke DV. Effect of protein-energy nutrition on the activity of hepatic microsomal drug-metabolizing enzymes in growing rats. J Nutr 1976; 106: 258-63.

[3] Basu TK, Dickerson JWT, Parke DV. Effect of dietary substitution of sucrose and constituent monosaccharides on the activity of aromatic hydroxylase and the level of cytochrome P-450 in hepatic microsomes of growing rats. Nutr Metab 1975; 18: 302-9.

[4] Anderson KE, Conney AH, Kappas A. Nutrition and oxidative drug metabolism in man: relative influence of dietary lipids, carbohydrate and protein. Clin Pharmacol Ther 1979; 26: 493-501.

[5] Sutton JL, Basu TK, Dickerson JW. Effect of large doses of ascorbic acid on the mixed-function oxidase system in guinea pig liver. Biochem Pharmacol 1982; 31: 1591-4.

[6] Basu TK. Effects of protein malnutrition and ascorbic acid on levels on drug metabolism. Can J Physiol Pharmacol 1983; 61: 295-301.

[7] Ioannides C. Effect of diet and nutrition on the expression of cytochromes P450. Xenobiotica 1999; 29: 109-54.

[8] Ioannides C. Pharmacokinetic interactions between herbal remedies and medicinal drugs. Xenobiotica 2002; 32: 451-78.

[9] Pantuck EJ, Pantuck EB, Garland WA, et al. Stimulatory effect of Brussel sprouts and cabbage on human drug metabolism. Clin Pharmacol Ther 1979; 25: 88-95.

[10] Kall MA, Clausen J. Dietary effect on mixed function P450 1A2 activity assayed by estimation of caffeine metabolism in man. Hum Exp Toxicol 1995; 14: 801-7.

[11] Kall MA, Vang O, Clausen J. Effects of dietary broccoli in human in vivo drug metabolizing enzymes: evaluation of caffeine, oestrone and chlorzoxazone metabolism. Carcinogenesis 1996; 17: 793-9.

[12] Kim RB, Wilkinson GR. Watercress inhibits human CYP2E1 activity in vivo as measured by chlorzoxazone 6-hydroxylation. Clin Pharmacol Ther 1996; 59: 170.

[13] Murray SS, Lake BG, Gray S, et al. Effect of cruciferous vegetable consumption on heterocyclic amine metabolism in man. Carcinogenesis 2001; 22: 1413-20.

[14] Waters DG, Young PJ, Agus C, et al. Cruciferous vegetable consumption alters the metabolism of the dietary carcinogen 2amino-1-methyl-6-phenylimidazo[4,5-b]pyridine (PhIP) in humans. Carcinogenesis 2004; 25: 1659-69.

[15] Ambrosone CB, McCann SE, Freudenheim JL, Marshall JR, Zhang $\mathrm{Y}$, Shields PG. Breast cancer risk in premenopausal women is inversely associated with consumption of broccoli, a source of isothiocyanates, but is not modified by GST genotype. J Nutr 2004; 134: 1134-8.

[16] Van Poppel G, Verhoeven DT, Verhagen H, Goldbohm RA. Brassica vegetables and cancer prevention. Epidemiology and mechanisms. Adv Exp Med Biol 1999; 472: 159-68.

[17] Joseph MA, Moysich KB, Freudenheim JL, et al. Cruciferous vegetables, genetic polymorphisms in glutathione $S$-transferases M1 and T1 and prostate cancer risk. Nutr Cancer 2004; 50: 206-13.

[18] Zhao H, Grossman HB, Hernandez LM, Dinney CP, Wu X. Dietary isothiocyanates, GSTM1, GSTT1, NAT2 polymorphisms and bladder cancer risk. Int J Cancer 2007; 120: 2208-13.

[19] Lin HJ, Probst-Hensch NM, Louie A, et al. Glutathione transferase null genotype, broccoli, and lower prevalence of colorectal adenomas. Cancer Epidemiol Biomarkers Prev 1998; 7: 647-52.

[20] Getahun SM, Chung F-L. Conversion of isothiocyanates in humans after ingestion of cooked watercress. Cancer Epidemiol Biomarkers Prev 1999; 8: 447-51.

[21] Hanlon N, Coldham N, Gielbert A, et al. Absolute bioavailability and dose-dependent pharmacokinetic behaviour of dietary doses of the chemopreventive isothiocyanate sulforaphane in rat. Br J Nutr 2008; 99: 559-64.

[22] Hanlon N, Coldham N, Gielbert, Sauer MJ, Ioannides C. Repeated intake of broccoli does not lead to higher plasma levels of sulforaphane in human volunteers. Cancer Lett 2009; In Press.

[23] Konsue N, Kirkpatrick J, Kuhnert N, King LJ, Ioannides C. Repeated oral administration modulates the pharmacokinetic behaviour of the chemopreventive agent phenethyl isothiocyanate in rats. Mol Nutr Food Res 2009; In Press

[24] Ji Y, Kuo Y, Morris ME. Pharmacokinetics of dietary phenethyl isothiocyanates in rats. Pharm Res 2005; 22: 1658-66.

[25] Shapiro TA, Fahey JW, Dinkova-Kostova AT, et al. Safety, tolerance, and metabolism of broccoli sprout glucosinolates and isothiocyanates: a clinical Phase I study. Nutr Cancer 2006; 55: 53-62. 
[26] Zhang Y. Cancer-preventive isothiocyanates: measurement of human exposure and mechanism of action. Mutat Res 2004; 555: $173-90$.

[27] Thornalley PJ. Isothiocyanates: mechanism of cancer chemopreventive action. Anti-Cancer Drugs 2002; 13: 331-8.

[28] Song L, Thornalley PJ. Effect of storage, processing and cooking on glucosinolate content of Brassica vegetables. Food Chem Toxicol 2007; 45: 216-24.

[29] Rungapamestry V, Duncan AJ, Fuller Z, Ratcliffe B. Effect of meal composition and cooking duration on the fate of sulforaphane following consumption of broccoli by healthy human subjects. Br J Nutr 2007; 97: 644-52.

[30] Conaway CC, Getahun SM, Liebes LL, et al. Disposition of glucosinolates and sulforaphane in humans after ingestion of steamed and fresh broccoli. Nutr Cancer 2001; 38: 468-78.

[31] Maheo K, Morel F, Langouet S, et al. Induction of cytochrome p450 and induction of glutathione S-transferases by sulforaphane in primary human and rat hepatocytes. Cancer Res 1997; 57: 364952

[32] Barcelo S, Gardiner JM, Gescher A, Chipman JK. CYP2E1mediated mechanism of anti-genotoxicity of the broccoli constituents sulforaphane. Carcinogenesis 1996; 17: 277-82.

[33] Yoxall V, Kentish P, Coldham N, Kuhnert N, Sauer MJ, Ioannides C. Modulation of hepatic cytochromes P450 and phase II enzymes by dietary doses of sulforaphane in rats: Implications for its chemopreventive activity. Int J Cancer 2005; 117: 356-62.

[34] Hanlon N, Okpara M, Coldham N, Sauer MJ, Ioannides C. Modulation of rat hepatic and pulmonary cytochromes P450 and Phase II enzyme systems by erucin, an isothiocyanate structurally related to sulforaphane. J Agric Food Chem 2008 ; 56 : 7866-71.

[35] Hanlon N, Coldham N, Sauer MJ, Ioannides C. Up-regulation of the CYP1 family in rat and human liver by the aliphatic isothiocyanates erucin and sulforaphane. Toxicology 2008; 252: 92-8.

[36] Hanlon N, Coldham N, Sauer MJ, Ioannides C. Modulation of rat pulmonary carcinogen-metabolising enzyme systems by the isothiocyanates erucin and sulforaphane. Chem-Biol Interact 2009; 177: 115-20.
[37] Guo Z, Smith TJ, Wang E, et al. Effect of phenethyl isothiocyanate, a carcinogenesis inhibitor, on xenobiotic-metabolizing enzymes and nitrosamine metabolism in rats. Carcinogenesis 1992; 13: 2205-10.

[38] Ishizaki H, Brady JF, Ning SM, Yang CS. Effect of phenethyl isothiocyanate on microsomal $\mathrm{N}$-nitrosodimethylamine metabolism and other monooxygenase activities. Xenobiotica 1990; 20: 255-64.

[39] Smith TJ, Guo Z, Li C, Ning SM, Thomas PE, Yang CS. Mechanisms of inhibition of 4-(methylnitrosamino)-1-(3-pyridyl)1-butanone bioactivation in mouse by dietary phenethyl isothiocyanate. Cancer Res 1993; 53: 3276-82.

[40] Konsue N, Ioannides C. Tissue differences in the modulation of rat cytochromes $\mathrm{P} 450$ and phase II conjugation systems by dietary doses of phenethyl isothiocyanate. Food Chem Toxicol 2008; 46 : 3677-83.

[41] Nakajima M, Yoshida R, Shimada N, Yamazaki H, Yokoi T. Inhibition and inactivation of human cytochrome P450 isoforms by phenethyl isothiocyanate. Drug Metab Dispos 2001; 29: 1110-3.

[42] Talalay P, Fahey JW. Phytochemicals from cruciferous plants protect against cancer by modulating carcinogen metabolism. J Nutr 2001; 131: 3027S-33S

[43] Hanlon N, Poynton CL, Coldham N, Sauer MJ, Ioannides C. The aliphatic isothiocyanates erucin and sulforaphane do not effectively up-regulate $\mathrm{NAD}(\mathrm{P}) \mathrm{H}$ : quinone oxidoreductase (NQO1) in human liver compared with rat. Mol Nutr Food Res 2009; 53: 836-44.

[44] Conaway CC, Yang Y-M, Chung F-L. Isothiocyanates as cancer chemopreventive agents: Their biological activities and metabolism in rodents and humans. Curr Drug Metab 2002; 3: 233-55.

[45] Steinbrecher A, Linseisen J. Dietary intake of individual glucosinolates in participants of the EPIC-Heidelberg cohort study. Ann Nutr Met 2009; 54: 87-96.

[46] Hecht SS. Inhibition of carcinogenesis by isothiocyanates. Drug Metab Rev 2000; 32: 395-411.

[47] Hanlon N, Konsue N, Coldham N, Sauer MJ, Ioannides C. Isothiocyanates enhance the metabolism of the heterocyclic amine IQ in rat, as exemplified by the urinary excretion of mutagens: lack of association with CYP1 activity. Nutr Cancer 2009; In Press.

(C) Ioannides et al.; Licensee Bentham Open.

This is an open access article licensed under the terms of the Creative Commons Attribution Non-Commercial License (http://creativecommons.org/licenses/by$\mathrm{nc} / 3.0 /$ ) which permits unrestricted, non-commercial use, distribution and reproduction in any medium, provided the work is properly cited. 